\title{
Acute renal failure in preeclampsia and eclampsia
}

\author{
Jayshree Mulik, Varsha Gaikwad*
}

Department of Obstetrics and Gynecology, Government Medical College and Hospital, Nagpur, Maharashtra, India

Received: 9 October 2018

Accepted: 27 October 2018

\section{*Correspondence:}

Dr. Varsha Gaikwad,

E-mail: varshagaikwadobgy@ rediffmail.com

Copyright: () the author(s), publisher and licensee Medip Academy. This is an open-access article distributed under the terms of the Creative Commons Attribution Non-Commercial License, which permits unrestricted non-commercial use, distribution, and reproduction in any medium, provided the original work is properly cited.

\begin{abstract}
Background: Incidence of acute renal failure (ARF) in preeclampsia and eclampsia is reported to be alarmingly high. Present study was conducted to evaluate the incidence of acute renal failure (ARF) in our institute, to study ARF associated risk factors and its complications along with pregnancy outcome evaluation.

Methods: All 812 patients of preeclampsia and eclampsia admitted in the department of obstetrics and gynecology during the study period at our institute were studied. Out of them, the 44 patients diagnosed with ARF were analyzed in detail in terms of maternal age, gravida, booked/unbooked, gestational age, associated complications, management and outcome of pregnancy.

Results: ARF was found to occur in $0.4 \%$ (2/501) cases of mild preeclampsia, in $16.76 \%(28 / 167)$ cases of severe preeclampsia and in $9.72 \%(14 / 144)$ cases of eclampsia. Intrauterine death $(14,31.82 \%)$ was the commonest complication followed by HELLP syndrome $(11,25.0 \%)$, post-partum hemorrhage $(8,18.18 \%)$ and maternal death $(7$, $15.9 \%)$. Out of 44 cases, $14(31.82 \%)$ had intrauterine death and $8(18.18 \%)$ had fresh stillbirth. Sixteen $(36.36 \%)$ had low birth weight babies. Total neonatal mortality in present study was observed in $5(11.36 \%)$ cases, 3 in severe preeclampsia group and 2 in eclampsia group.

Conclusions: Acute renal failure is seen frequently in patients of severe preeclampsia and eclampsia with associated complications. Maternal and perinatal mortality and morbidity can be prevented in them with earlier detection and management of complications.
\end{abstract}

Keywords: Acute renal failure, Eclampsia, Preeclampsia

\section{INTRODUCTION}

Hypertensive disorders of pregnancy, including preeclampsia and HELLP syndrome (Haemolysis, elevated liver enzymes and low platelet count) affect 2$7 \%$ of pregnancies. ${ }^{1}$ Preeclampsia and eclampsia together constitute one of the top three causes of maternal mortality and is the leading cause of maternal and fetal morbidity. ${ }^{2}$

In preeclampsia, vasospasm and glomerular capillary endothelial swelling (glomerular endotheliosis) lead to reduction in renal plasma flow and glomerular filtration rate ranging from $25 \%$ in mild to $50 \%$ in severe cases. ${ }^{3}$
Acute renal failure (ARF) secondary to preeclampsia and eclampsia is most probably due to acute tubular necrosis. It has been suggested that glomerular capillary obstruction resulting from the swelling of glomerular endothelial cells lead to post glomerular ischemia and acute tubular necrosis.

Incidence of ARF in preeclampsia and eclampsia is reported at $\sim 5 \%$; with the occurrence being usually complicated by abruptio placentae, disseminated intravascular coagulation (DIC) and HELLP syndrome, leading to increased hospital stay and poor perinatal outcome. ${ }^{4}$ This prompted us to evaluate the incidence of acute renal failure (ARF) in our institute, to study ARF 
associated risk factors and its complications along with pregnancy outcome evaluation.

\section{METHODS}

Hospital based observational study conducted in Department of Obstetrics and Gynecology, Government Medical College and Hospital, Nagpur (M.S.), India from August 2006 to July 2007. All patient of preeclampsia and eclampsia admitted in the department of obstetrics and gynecology during the study period at our institute.

\section{Exclusion criteria}

- Cases of chronic hypertension

- Known case of chronic renal disease

- Known case of epilepsy

- Meningitis, Encephalitis

- Intracranial tumours

The diagnosis of preeclampsia and eclampsia was established in accordance with National High Blood Pressure Education Program Working Group on High Blood Pressure in Pregnancy. ${ }^{5}$

- Preeclampsia: Blood pressure more than or equal to $140 / 90 \mathrm{mmHg}$ after 20 weeks of gestation on two occasions at least 6 hours apart and proteinuria > $300 \mathrm{mg} / 24$ hours or $2+$ or more on dipstick.

- Eclampsia: Seizures or coma that cannot be attributed to other cerebral condition in obstetric patients with preeclampsia after 20 weeks of gestation.

- $\quad$ Acute Renal Failure (ARF):

○ Serum Creatinine $>1.5 \mathrm{mg} / \mathrm{dl}$

- Urine output $<400 \mathrm{ml}$ in 24 hours, $<100 \mathrm{ml}$ in 4 hours, $<25$ to $30 \mathrm{ml} /$ hour over 2 consecutive hours.

Out of total 812 patients of pre-eclampsia and eclampsia, renal failure was diagnosed in 44 patients. These 44 patients were analysed in detail in terms of maternal age, gravida, booked/unbooked, gestational age, associated complications, management and outcome of pregnancy. The data was collected as per a predesigned and validated proforma. Demographic information, and detailed and relevant history was recorded, followed by general, systemic and per-abdomen examination. Patient's 24hour urine output was recorded. All the patients were subjected to list of investigations, most essentially proteinuria on dipstick and 24-hour albumin and serum creatinine, among others. Pregnancy outcome i.e. spontaneous/induced, full term/preterm, mode of delivery were noted. Maternal and perinatal mortality and morbidity were assessed. The data was analysed using SPSS (version 20); by applying chi-square test and ANOVA wherever applicable. Multiple comparison was done by Bonferroni test. For small sample, Fischer Exact test was applied.
Approval from Institutional Ethics Committee was obtained before start of the study. Informed written consent was obtained from each patient before participation in the study.

\section{RESULTS}

During the period of one year from August 2006 to July 2007 , total number of deliveries in our hospital was 13518. Out of these, 812 women had preeclampsia/eclampsia, giving us the incidence of $6.0 \%$. Out of 812 patients, $61.7 \%$ patients were of mild preeclampsia, $20.56 \%$ of severe preeclampsia and $17.74 \%$ had eclampsia.

A total of $44(5.42 \%)$ patients developed acute renal failure (ARF) as a complication of preeclampsia or eclampsia. ARF was found to occur in $0.4 \%(2 / 501)$ cases of mild preeclampsia, in $16.76 \%$ (28/167) cases of severe preeclampsia and in $9.72 \%(14 / 144)$ cases of eclampsia. Thus, out of 44 patients of ARF, 2 (4.55\%) were of mild, $28(63.64 \%)$ were of severe preeclampsia and $14(31.81 \%)$ cases were of eclampsia. All patients of mild preeclampsia with ARF were below 25 years of age. Majority of patients of severe preeclampsia and eclampsia were of age group 21-25 years, i.e. $60.71 \%$ and $71.42 \%$ respectively.

Out of 44 ARF patients, $65.9 \%$ (29/44) of patients were primigravida and $34.1 \%(15 / 44)$ were second gravida and above $(\mathrm{p}<0.05)$. Total of $88.64 \%(39 / 44)$ ARF patients were unbooked and only $11.36 \%(5 / 44)$ were booked cases. Out of 39 unbooked cases, 5 were referred as ARF from outside hospital. As for gestational age, $100 \%$ cases of mild preeclampsia with ARF were term (>37 weeks). In severe preeclampsia, the incidence of ARF was found to be $28.57 \%$ in both groups of gestational age of 28 to 37 weeks and $>37$ weeks. In eclampsia, $35.71 \%$ cases were of gestational age 32-34 weeks. All cases of eclampsia were emergency admissions and unbooked ones. As for mode of delivery, 63.64\% (28) patients delivered vaginally, while $36.36 \%$ (16) patients required LSCS.

Table 1 details the associated pregnancy complications in patients with ARF. Intrauterine death (14, 31.82\%) was the commonest complication followed by HELLP syndrome $(11,25.0 \%)$, post-partum hemorrhage (8, $18.18 \%)$ and maternal death $(7,15.9 \%)$. No complications were reported in the two patients of mild preeclampsia. Out of 7 maternal deaths, 4 were had severe preeclampsia and 3 had eclampsia. Out of 44 patients of ARF, $50 \%$ were managed by fluid monitoring only. All cases of mild preeclampsia with ARF recovered fully with fluid monitoring alone. In severe preeclampsia, $12(42.86 \%)$ patients required diuretics and $4(14.28 \%)$ patients required dialysis for management. In Eclampsia, $5(35.71 \%)$ and $1(7.14 \%)$ patients required diuretics and dialysis respectively. When serum creatinine was assessed, in patients with serum creatinine in the range of 
$1.5-3 \mathrm{mg} / \mathrm{dl}, 17(60.71 \%)$ cases were managed by fluid monitoring and $11(39.29 \%)$ required diuretics, with no one requiring dialysis. In patients with serum creatinine $3-4.5 \mathrm{mg} / \mathrm{dl}, 4(50 \%)$ cases each required diuretics and fluid monitoring, and no one required dialysis. But in patients with serum creatinine $>4.5 \mathrm{mg} / \mathrm{dl}$ and $62.5 \%$ patients required dialysis, $25 \%$ were managed by diuretics.

Table 1: Associated pregnancy complications in ARF.

\begin{tabular}{|llllll} 
Complications & Mild-preeclampsia & Severe- preeclampsia & Eclampsia & Total & p-value \\
\hline Intrauterine Death & - & $8(28.57 \%)$ & $6(42.86 \%)$ & $14(31.82 \%)$ & 0.454 \\
\hline HELLP Syndrome & - & $7(25.0 \%)$ & $4(28.57 \%)$ & $11(25.0 \%)$ & 0.683 \\
\hline Post-Partum hemorrhage & - & $6(21.43 \%)$ & $2(14.28 \%)$ & $8(18.18 \%)$ & 0.798 \\
\hline Maternal Death & - & $4(14.28 \%)$ & $3(21.42 \%)$ & $7(15.9 \%)$ & 0.767 \\
\hline DIC & - & $4(14.28 \%)$ & $1(7.14 \%)$ & $7(5.9 \%)$ & 0.725 \\
\hline Abruptio Placantae & - & $6(21.43 \%)$ & $1(7.14 \%)$ & $7(5.9 \%)$ & 0.402 \\
\hline Aspiration Pneumonia & - & $1(3.57 \%)$ & $1(7.14 \%)$ & $2(4.55 \%)$ & 0.365 \\
\hline Pulmonary Edema & - & - & $1(7.14 \%)$ & $1(2.27 \%)$ & 0.334 \\
\hline
\end{tabular}

Table 2: Perinatal outcome amongst study participants with ARF (n=44).

\begin{tabular}{|llllll|}
\hline Complications & Mild-preeclampsia & Severe-preeclampsia & Eclampsia & Total & p-value \\
\hline Low birth weight & - & $9(32.14 \%)$ & $7(50 \%)$ & $16(36.36 \%)$ & 0.289 \\
\hline Intrauterine death & - & $8(28.57 \%)$ & $6(42.86 \%)$ & $14(31.82 \%)$ & 0.454 \\
\hline Fresh stillbirth & - & $7(25 \%)$ & $1(7.14 \%)$ & $8(18.18 \%)$ & 0.388 \\
\hline Neonatal Mortality & - & $3(10.71 \%)$ & $2(14.28 \%)$ & $5(11.36 \%)$ & 0.515 \\
\hline Sepsis & - & $2(7.14 \%)$ & - & $2(4.55 \%)$ & - \\
\hline Respiratory Distress & - & $1(3.57 \%)$ & - & $1(2.27 \%)$ & - \\
\hline Congenital Anomaly & - & - & $1(7.14 \%)$ & $1(2.27 \%)$ & - \\
\hline
\end{tabular}

Mean hospital stays in 3 groups of mild and severe preeclampsia and eclampsia were $10.0+2.41,12.53+$ 6.86 and $13.0+9.46$ days respectively; the difference being statistically insignificant. The perinatal outcome in ARF cases is as detailed in Table 2. Out of 44 cases, 14 $(31.82 \%)$ had intrauterine death and $8(18.18 \%)$ had fresh stillbirth. Sixteen $(36.36 \%)$ had low birth weight babies. Total neonatal mortality in present study was observed in $5(11.36 \%)$ cases, 3 in severe preeclampsia group and 2 in eclampsia group. Mean birth weight in severe preeclampsia $(1.68+0.63 \mathrm{Kgs})$ and eclampsia $(1.56+$ $0.42 \mathrm{Kgs})$ group was significantly less as compared to that in mild preeclampsia group $(2.7+0.50 \mathrm{Kgs})$ $(\mathrm{p}<0.05)$. Out of 7 maternal deaths, 4 patients had serum creatinine level in the range of $1.5-3 \mathrm{mg} / \mathrm{dl}, 2$ between $3-$ $4.5 \mathrm{mg} / \mathrm{dl}$ and 2 patients had serum creatinine level of $>4.5 \mathrm{mg} / \mathrm{dl}$. Out of 7 maternal deaths, only 1 was booked with us. Remaining 6 were referred cases. Out of these 6 , 3 patients had zero antenatal visits. In all 44 cases of ARF < Ultrasound KUB was done to check for renal parenchymal disease (RPD). IN 27 patients, RPD was detected. Out of these 27 patients, 16 (59.26\%) had ARF and $11(40.74 \%)$ didn't have ARF.

\section{DISCUSSION}

Pregnancies complicated by severe preeclampsia and eclampsia are characterised by functional derangement of multiple organ systems such as cardiovascular, renal, hepatic, hematologic and central nervous system. In addition, these pregnancies are associated with multiple complications including abruptio placentae, fetal death, DIC, HELLP syndrome, pulmonary edema, sepsis and postpartum hemorrhage that requires massive transfusion. Consequently, the above changes predispose such patients to an increased risk of acute renal failure. ${ }^{4}$ The present study was conducted in order to assess the incidence, risk factors and pregnancy outcomes in patients of ARF in preeclampsia and eclampsia.

The incidence of eclampsia in the present study was $1.07 \%$ (144 out of 13518 patients). Sanyal et al reported it at $2.6 \%$, whereas Verawalla et al observed it to be as low as $0.179 \% .^{6,7}$ The variation in the incidence of eclampsia seems mainly due to location of the study centres. Hospital serving predominantly rural population have higher incidence (Sanyal et al), since the level of antenantal care in the region is inferior to the urban population (studied by Verawalla et al). ${ }^{6,7}$ The incidence of ARF in severe preeclampsia and eclampsia group in the study carried out by Thomas et al and Prakash et al was $6.38 \%$ and $9.72 \%$ respectively. ${ }^{8,9}$ In the present study, it was $13.5 \%$. The incidence of ARF in eclampsia group in various studies ranged from $4-7.8 \% .^{5,8-11}$ Only one study by Mjahed et al reported the incidence at $25.8 \%$, which could be explained by the fact that this 
particular study was carried out in the intensive care unit of University medical centre. ${ }^{12}$ In the present study, the incidence of ARF in eclampsia group was found to be $9.72 \%$.

Mean maternal age in present study was $24.71+4.04$ years, which is comparable to previous similar studies. ${ }^{8-12}$ As for the percentage of primigravida amongst study participants, Mjahed et al found $52 \%$ of ARF in eclampsia cases to be primigravida, what we observed at $64.28 \% .{ }^{12}$ Amongst those with ARF in severe preeclampsia, Drakeley et al reported the incidence of primigravida to be $43 \%$ against our finding of $57.14 \%$. Thus, the results are largely comparable. ${ }^{13}$ The percentage of patients without prior antenatal care was $12.5 \%$ in the study by Drakeley et al, with all the 9 cases not having any antenatal visit anywhere. ${ }^{13}$

The percentage in present study was $88.64 \%$. Out of these unbooked cases $(34 / 44), 16(14.02 \%)$ had no antenatal check-up at all, while fifteen $(38.46 \%)$ had less than 3 and $8(20.51 \%)$ had more than 3 antenatal visits. The difference may be due to the population served by our hospital and being a tertiary referral centre, majority of complicated cases are referred from primary or secondary level centres. The mean gestational age was $34.4+3.9$ weeks in the study by Mjahed et al and was 32 weeks in the study by Drakeley et al. ${ }^{12,13}$ The corresponding values were comparable in the present study at $34.5+3.61$ weeks in eclampsia and $35.32+3.67$ weeks in severe preeclampsia.

Presence of associated complications with ARF was studied in cases of preeclampsia and eclampsia. With respect to complications in eclampsia subgroup, percentage of DIC, abruptio placentae and postpartum hemorrhage was more in the study by Mjahed et al than present study. ${ }^{12}$ This is likely because that particular study was carried out in an ICU setting, where usually more complicated cases are managed. In study in patients of severe preeclampsia with ARF by Drakeley et al, HELLP syndrome was associated with ARF in $44.44 \%$ cases, Abruptio Placentae in $31.94 \%$ cases and pulmonary edema in $6.94 \%$ cases $^{13}$ In the present study, these complications were observed in much less proportions, with HELLP syndrome in $25 \%$ cases and Abruptio Placentae in $21.43 \%$ cases only. This difference is may be because at the time of study by Drakeley et al13, the majority of hospital admissions were for complications of severe preeclampsia. ${ }^{13}$ The percentage of associated complications in preeclampsia (combined) in the study by Sibai et al was abruptio placentae (50\%), postpartum hemorrhage $(93 \%)$ and pulmonary edema $(61 \%)$. Compared to these values, the percentage of complications in much less in present study, i.e. $15.90 \%$, $2.27 \%$ and $18.18 \%$ respectively. ${ }^{4}$

As for the mode of delivery, in the study by Mjahed et al, $63 \%$ patients with eclampsia required caesarean section, compared to $28.57 \%$ in the present study. ${ }^{12}$ In the study by Sibai et al, $61 \%$ patients from all hypertensive disorders of pregnancy required caesarean section compared to $36.36 \%$ in the present study. ${ }^{4}$

With respect to management of ARF by dialysis, Mjahed et al observed that $32.61 \%$ cases of eclampsia patients required dialysis, as compared to $7.14 \%$ eclampsia patients in the present study. The difference could be due to the higher proportion of complicated cases of eclampsia being referred in the Mjahed study. ${ }^{12}$ In the study by Drakeley et al, $9.72 \%$ patients of severe preeclampsia required dialysis, which was comparable to what we observed in the present study (14.28\%). ${ }^{13}$ Sibai et al reported $50 \%$ patients of $\mathrm{PIH}$ requiring dialysis, against $11.36 \%$ in present study. ${ }^{4}$ The high percentage reported in the Sibai study could be due to the fact that majority of patients had marked functional derangement of multiple organ systems and the study series were largely selective, i.e. referred patients. The mean serum creatinine level in the patients requiring dialysis in the Sibai study was $10.8 \mathrm{mg} / \mathrm{dl}$, as against $8.02+2.73 \mathrm{mg} / \mathrm{dl}$ reported in the present study, corroborating the above observation.

Perinatal mortality in severe preeclampsia patients in the study by Drakeley et al was reported at $37.5 \%$. Corresponding value in the present study was $64.29 \% .^{13}$ This may be due to very high number of IUD (mostly referred cases), i.e. 14/44 (31.82\%) along with 8/44 $(18.18 \%)$ cases of fresh stillbirth. Mjahed et al studied maternal mortality in eclampsia and reported the incidence of $32.6 \%$, as against our finding of $21.42 \% .^{12}$ This high incidence was mainly due to higher proportion of DIC (37\% vs $7.14 \%$ ), abruptio placentae $(28.3 \%$ bs $7.14 \%$ ) and postpartum hemorrhage (23.9\% vs $14.28 \%$ ). Sibai et al studied maternal mortality in all patients of preeclampsia and eclampsia together and reported the incidence at $11.11 \%{ }^{4}$ The corresponding value in the present study was coparable $(15.9 \%)$.

\section{CONCLUSION}

In conclusion, acute renal failure is seen frequently in patients of severe preeclampsia and eclampsia with associated complications. It is prudent to say that if these complications are detected earlier and managed properly, renal failure can be prevented. This will serve well the larger goal of preventing maternal and perinatal mortality and morbidity.

\section{Funding: No funding sources \\ Conflict of interest: None declared}

Ethical approval: The study was approved by the Institutional Ethics Committee

\section{REFERENCES}

1. Sibai B, Dekker G, Kupferminc M. Preeclampsia. Lancet 2005;365(9461):785-99. 
2. Sibai B. Prevention of preeclampsia: a big disappointment. Am J Obstet Gynaecol 1998;179(5):1275-78.

3. Gabbe SG, Niebyl JR, Simpson JL, Landon MB, Galan HL, Jauniaux ERM, and Driscoll DA: Obstetrics: Normal and Problem Pregnancies, Saunders Elsevier, 6th Edition, 2012.

4. Sibai BM, Villar MA, Mabie BC. Acute renal failure in hypertensive disorders of pregnancy. Am J Obstet Gynecol 1990;162(3):777-83.

5. Report of the National High Blood Pressure Education Program Working Group on High Blood Pressure in Pregnancy. Am J Obstet Gynecol 2000;183:S1-S22.

6. Sanyal MK, Bhattacharjee A, Pattanyak A. A clinical review of eclampsia in a rural medical college of West Bengal (A three and half year study). J Obstet Gynecol India. 1987;37:797-802.

7. Verawalla NY, Ghamande S, Ingle KM. A five-year analysis of eclampsia. J Obstet Gynecol India 1989;513-15.

8. Thomas T, Jophy R, Mhaskar A, Misquith D. Are we increasing serious maternal morbidity by postponing termination of pregnancy in severe preeclampsia/eclampsia? J Obstet Gynecol India. 2005;25(4):347-51.

9. Prakash J, Pandey CK, Singh AK, Kar B. Hypertension in pregnancy: hospital-based study. J Assoc Physicians India. 2006;54(R):273-8.

10. Lopez-Liera M. Complicated eclampsia. Fifteen years' experience in a referral medical centre. Am J Obstet Gynecol 1982;142(1):28-35.

11. Mattar F, Sibai BM. Eclampsia: Risk factor for maternal mortality. Am J Obstet Gynecol. 2000;182(2):306-12.

12. Mjahed K, Alaovi SY, Barrou L. Acute renal failure during eclampsia: Incidence, risk factors and outcome in intensive care unit. Renal failure 2004;26(3):215-21.

13. Drakeley A, Roure PA, Anthony J, Penny J. Acute renal failure complicating severe preeclampsia requiring admission to an obstetric intensive care unit. Am J Obstet Gynecol 2002;186(2):253-6.

Cite this article as: Mulik J, Gaikwad V. Acute renal failure in preeclampsia and eclampsia. Int $\mathbf{J}$ Reprod Contracept Obstet Gynecol 2018;7:5097-101. 